\title{
Bidirectional Plasticity of Purkinje Cells Matches Temporal Features of Learning
}

\author{
Daniel Z. Wetmore, ${ }^{1}$ Dan-Anders Jirenhed, ${ }^{1,3}$ Anders Rasmussen, ${ }^{3}$ Fredrik Johansson, ${ }^{3}$ Mark J. Schnitzer, ${ }^{1,2}$ and \\ Germund Hesslow ${ }^{3}$ \\ ${ }^{1}$ James H. Clark Center for Biomedical Engineering and Sciences, and ${ }^{2}$ Howard Hughes Medical Institute, Stanford University, Stanford, California 94305 , \\ and ${ }^{3}$ Lund University, Department of Experimental Medicine, S 22184 Lund, Sweden
}

\begin{abstract}
Many forms of learning require temporally ordered stimuli. In Pavlovian eyeblink conditioning, a conditioned stimulus (CS) must precede the unconditioned stimulus (US) by at least about $100 \mathrm{~ms}$ for learning to occur. Conditioned responses are learned and generated by the cerebellum. Recordings from the cerebellar cortex during conditioning have revealed CS-triggered pauses in the firing of Purkinje cells that likely drive the conditioned blinks. The predominant view of the learning mechanism in conditioning is that long-term depression (LTD) at parallel fiber (PF)-Purkinje cell synapses underlies the Purkinje cell pauses. This raises a serious conceptual challenge because LTD is most effectively induced at short CS-US intervals, which do not support acquisition of eyeblinks. To resolve this discrepancy, we recorded Purkinje cells during conditioning with short or long CS-US intervals. Decerebrated ferrets trained with CS-US intervals $\geq 150 \mathrm{~ms}$ reliably developed Purkinje cell pauses, but training with an interval of 50 ms unexpectedly induced increases in CS-evoked spiking. This bidirectional modulation of Purkinje cell activity offers a basis for the requirement of a minimum CS-US interval for conditioning, but we argue that it cannot be fully explained by LTD, even when previous in vitro studies of stimulus-timing-dependent LTD are taken into account.
\end{abstract}

Key words: cerebellum; conditioning; learning; Purkinje cells; temporal; timing

\section{Introduction}

Early theories of associative learning and synaptic plasticity emphasized temporal contiguity of neural activity (Hebb, 1949), but these concepts fail to account for learning that requires stimuli with a prescribed temporal order (Gallistel, 1990). To account for such learning, spike-timing-dependent plasticity (STDP) has been proposed as a mechanism (Dan and Poo, 2006; Citri and Malenka, 2008). However, most studies of STDP have been done in vitro, so the relationship between synaptic plasticity and timing-dependent behavioral learning has not been investigated for most neural circuits.

A well-known example of timing-dependent learning is eyeblink conditioning where pairing a neutral conditioned stimulus (CS) with a blink-eliciting unconditioned stimulus (US) leads to the acquisition of an adaptively timed conditioned response (CR) that reaches its maximum close to the expected onset of the US (Kehoe and Macrae, 2002). Eyeblink conditioning requires a

\footnotetext{
Received June 30, 2013; revised Dec. 12, 2013; accepted Dec. 19, 2013.

Author contributions: D.Z.W., D.-A.J., M.J.S., and G.H. designed research; D.Z.W., D.-A.J., A.R., and F.J. performed research; D.Z.W. analyzed data; D.Z.W. and G.H. wrote the paper.

This work was supported by grants from the Swedish Research Council to the Linnaeus (entre for Cognition, Communication and Learning at Lund University (349-2007-8695) and G.H. (09899), grants from the Söderberg and Crafoord foundations to G.H., a National Science Foundation predoctoral fellowship to D.Z.W., a Swedish Research Council postdoctoral fellowship for work on the cerebellum to D.-A.J., and grants from the NIH and the Klingenstein, Sloan, and Packard Foundations to M.J.S.

Correspondence should be addressed to Germund Hesslow at the above address. E-mail: germund.hesslow@med.lu.se.

DOI:10.1523/JNEUROSCI.2883-13.2014

Copyright $\odot 2014$ the authors $\quad 0270-6474 / 14 / 341731-07 \$ 15.00 / 0$
}

minimum CS-US interval [interstimulus interval (ISI)] of about $100 \mathrm{~ms}$. At shorter ISIs, learning is unreliable or absent (Schneiderman and Gormezano, 1964; Smith, 1968; Smith et al., 1969; Salafia et al., 1980).

The cerebellar cortex is required for the acquisition of welltimed eyeblink CRs (Hesslow and Yeo, 2002; Kellett et al., 2010). Mossy (MF) and climbing fiber (CF) inputs to the cerebellum transmit information about the CS and US, respectively (Hesslow and Yeo, 2002). Conditioning with an ISI of $>200 \mathrm{~ms}$ causes cerebellar Purkinje cells to develop a suppression of simple spike firing in response to the CS (Hesslow and Ivarsson, 1994; Jirenhed et al., 2007). This pause in Purkinje cell firing, the Purkinje cell CR, is required for an overt CR (Hesslow, 1994b) and shares important properties with it such as adaptive timing, extinction, and savings (Jirenhed et al., 2007; Svensson et al., 2010; Jirenhed and Hesslow, 2011a,b). However, proposed cellular mechanisms for learning Purkinje cell CRs cannot fully account for the requirement of a minimum ISI for conditioning.

The Marr (1969), Albus (1971), and Ito et al. (1982) theory of motor learning proposes that convergent CF and PF input to Purkinje cells leads to long-term depression (LTD) of PF synapses on Purkinje cells. A wealth of evidence supports the existence of LTD, and it is a widely shared assumption that LTD is the mechanism behind the Purkinje cell pause response (Yamazaki and Tanaka, 2009). This creates a serious conceptual challenge. LTD is induced by PF and CF inputs that are simultaneous or close together in time (Ito, 2001). Some in vitro studies suggest that LTD is strongest for PF-CF intervals of $\sim 100 \mathrm{~ms}$ (Chen and 
Thompson, 1995; Wang et al., 2000; Safo and Regehr, 2008), but these studies also find LTD with simultaneous PF-CF input. Thus, if LTD is the synaptic mechanism underlying conditioning, training at short ISIs would be expected to lead to acquisition of CRs. Thus, either no Purkinje cell CRs develop with short ISIs, or they do occur but are not expressed as overt behavior (Wetmore et al., 2008). To address this paradox, we recorded Purkinje cells in decerebrate ferrets during conditioning with various ISIs.

\section{Materials and Methods}

Subjects for Purkinje cell recording experiments were 48 male ferrets (4-12 months, $1-2$ $\mathrm{kg}$ ) decerebrated under propofol anesthesia (10 mg/ml Diprivan; AstraZeneca). Subsequent Purkinje cell recordings occurred without anesthesia. The experimental setup is illustrated in Figure 1A. Techniques for the surgery, mapping of cerebellar cortex, placement of stimulation electrodes, choice of stimulation parameters, and Purkinje cell recording were as described in previous work from our lab (Jirenhed et al., 2007; Jirenhed and Hesslow, 2011a). MF stimulation consisted of $0.1 \mathrm{~ms}$ pulses at $50 \mathrm{~Hz}$ for $300 \mathrm{~ms}$ $(70-150 \mu \mathrm{A})$. CF stimulation consisted of two sets of five $0.1 \mathrm{~ms}(50-700 \mu \mathrm{A})$ pulses at 500 $\mathrm{Hz}$, with $20 \mathrm{~ms}$ between the onsets. The total US duration was therefore $28 \mathrm{~ms}$. Trials were delivered with an intertrial interval of $15 \mathrm{~s}$. Purkinje cell responses to the CS were probed with $40 \mathrm{CS}$-alone trials before training and between paired CS-US sessions that lasted 15-60 min.

The analysis workflow for Purkinje cell firing data included several steps. First, Purkinje cell spikes were identified with Spike2 software after high-pass filtering with a cutoff frequency of $1 \mathrm{kHz}$ (Cambridge Electronic Design). Simple and complex spike data were combined for analysis with custom MATLAB programs. Purkinje cell firing is variable, so spike data from each trial were smoothed with a Gaussian distribution $(\sigma=20 \mathrm{~ms})$, and then averaged across all trials of a CS-alone session to estimate the CS-evoked firing rate, $m(t)$. In some cases, spontaneous Purkinje cell firing varied between CS-alone sessions, so all $m(t)$ were normalized for across-session comparison according to $q(t)=m(t) / b-$ 1 , where $b=\Sigma \delta\left(t-t^{\prime}\right) / 0.2$ for $-0.2 \mathrm{~s}<t^{\prime}<0 \mathrm{~s}$, and $t=0$ is defined as CS onset. To quantify changes in CS-evoked Purkinje cell firing after training, we computed $r=\left[\left(c_{n} / b_{n}-c_{1} / b_{1}\right)-1\right]$, where $b$ is the baseline spike rate as defined above, $c$ is the spike rate during the CS defined as for $b$, with $0 \mathrm{~s}<t^{\prime}<0.2 \mathrm{~s}$, and the final CS-alone session recorded is designated by the subscript $n$. The time course of modulation after training was derived from smoothed, averaged, and normalized data from pretraining and posttraining CS-alone sessions according to $g(t)=q(t)_{n}$ $-q(t)_{1}$. We estimated the population response among a group of Purkinje cells recorded using the same ISI condition by averaging all $g(t)$.

Some data for 200 and $300 \mathrm{~ms}$ ISIs were taken from previously published data sets that did not always include CS-alone sessions (Jirenhed et al., 2007; Jirenhed and Hesslow, 2011b). We analyzed data from paired training sessions and masked spikes beginning $20 \mathrm{~ms}$ before US onset for these ISIs to exclude US-evoked spiking from the analysis.

For eyeblink conditioning studies, animals were decerebrated, but the cerebellar dura remained intact. The animals received no muscle relaxants. Pairs of insulated stainless-steel wires were used for recording eyelid
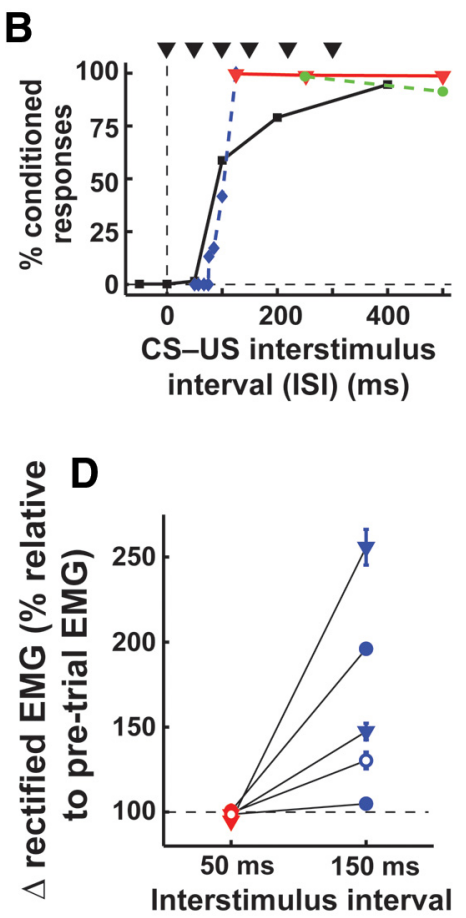

Figure 1. Decerebrate ferret schematic and eyeblink conditioning behavior. $\boldsymbol{A}$, For eyeblink conditioning studies, the CS and US were delivered through electrode pairs in the forelimb and periocular region, respectively. Behavioral responses were monitored

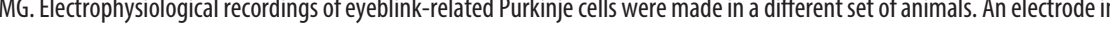
schneiderman and Gormezano (1964; dotted green line and circles). Black triangles indicate ISIs used for Purkinje cell recordings (2008)]. C, We trained decerebrate ferrets with a 45 or $145 \mathrm{~ms}$ ISI to confirm the temporal (blue), and extinction of the (R after subsequent training with a $45 \mathrm{~ms}$ ISI in the same animal (red). Red and blue reverse (triangles). Open symbols indicate the subject presented in $\boldsymbol{C}$.

electromyogram (EMG) and for delivering a forelimb CS (1 ms pulse width, $50 \mathrm{~Hz}, 300 \mathrm{~ms}, 1.0-1.5 \mathrm{~mA}$ ) and periocular US (1 ms pulse width, $500 \mathrm{~Hz}, 10 \mathrm{~ms}, 3.0 \mathrm{~mA}$ ). Animals were trained with 45 and $145 \mathrm{~ms}$ ISIs. For eyelid and forelimb stimuli, the transduction of CF activity to the cerebellar cortex is delayed by $\sim 5 \mathrm{~ms}$ more than that of MF activity, so these ISIs correspond to 50 and 150 ms ISIs in Purkinje cell recording studies that used direct MF and CF stimulation.

Three ferrets were trained with the long ISI first, followed by the short ISI. Two other animals were trained with the reverse ordering. Animals were trained until eyeblink CRs occurred on at least $\sim 70 \%$ of trials ( $2-7$ $\mathrm{h}$ per ISI). Each 30 min training block was composed of 12 sets of 10 trials (9 paired, 1 CS-alone), followed by 10 CS-alone trials. High-pass filtered EMG recordings ( $1 \mathrm{kHz}$ ) were rectified, binned (10 ms bin width), and normalized to the mean EMG value during the $200 \mathrm{~ms}$ preceding trial onset. Conditioning was quantified for the period extending from $50 \mathrm{~ms}$ before to $50 \mathrm{~ms}$ after expected US onset in a block of CS-alone trials. All $p$ values are from two-sample, two-tailed $t$ tests with no assumption of equal population variances.

\section{Results}

Eyeblink conditioning in decerebrate ferrets

In rabbits, acquisition of a CR requires a minimum ISI of $\sim 100$ $\mathrm{ms}$ (Fig. $1 B$ ), but short ISIs have not been tested in other species. To confirm that the principle of a minimum ISI applies in decerebrate ferrets, we performed eyeblink conditioning with a mild 
A

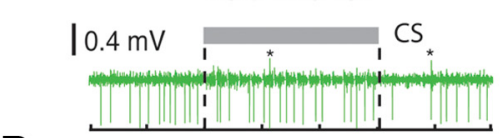

B
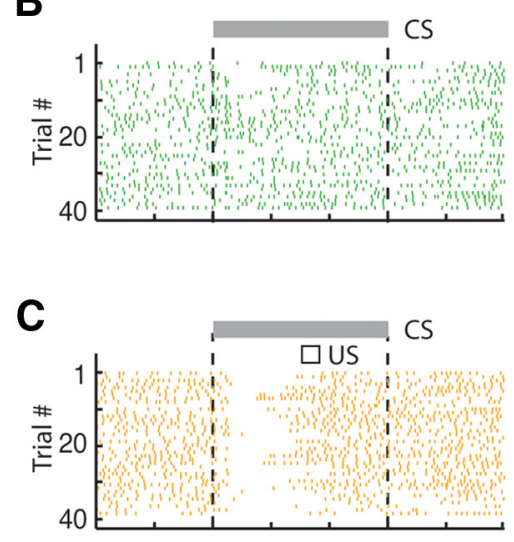

D

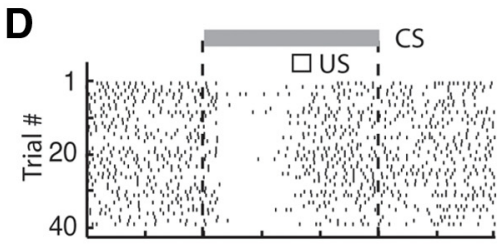

E

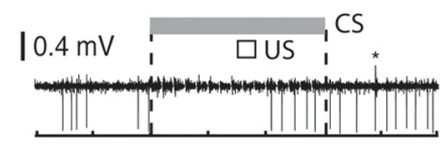

$\mathbf{F}$

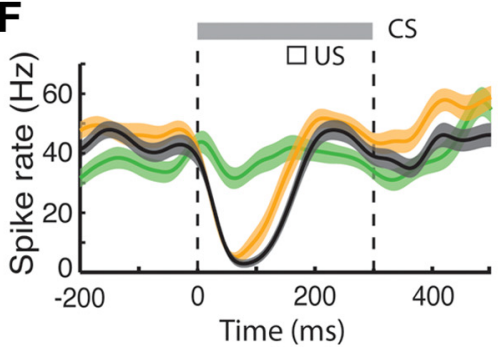

G

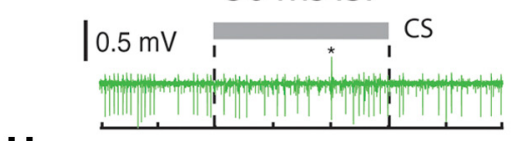

H
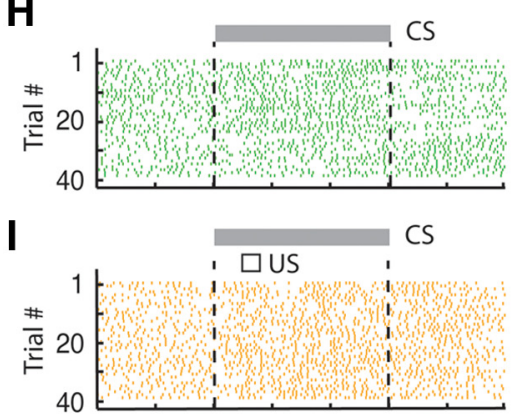

$\mathbf{J}$
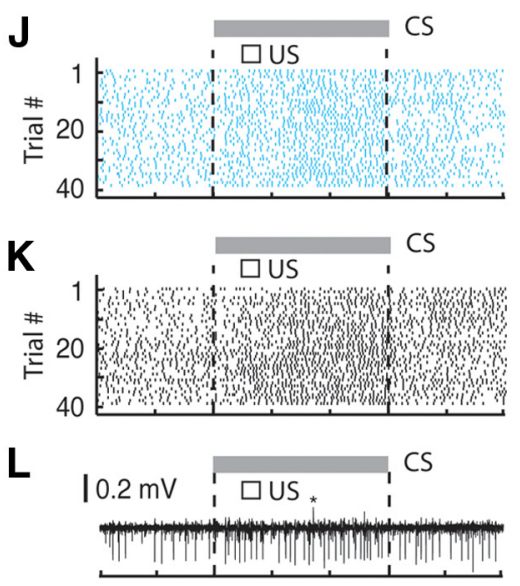

M

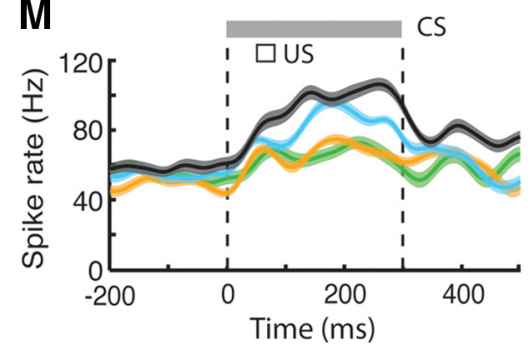

Figure 2. The ISI used for training determines the direction of CS-evoked Purkinje cell modulation. $\boldsymbol{A}-\boldsymbol{E}$, In a representative Purkinje cell, training with an ISI of 150 ms generated a CS-evoked pause. Learned changes in firing were monitored during CS-alone sessions of 40 trials before training $(\boldsymbol{A}, \boldsymbol{B})$, after 45 min of paired training $(\boldsymbol{C})$, and after an additional 20 min of training $(\boldsymbol{D}$, E). Gray and white boxes indicate the timing of CS presentation and US delivery during the most recent paired CS-US training session, respectively $(\boldsymbol{A}-\boldsymbol{M})$. Asterisks indicate complex spikes. Shaded regions represent the SEM. $\boldsymbol{F}$, Smoothed and averaged data from $\boldsymbol{B}-\boldsymbol{D}$ show a pause in (S-evoked firing after training (orange and black curves) relative to the pretraining baseline (green curve). $\mathbf{G}-\boldsymbol{L}$, In another cell, training with an ISI of $50 \mathrm{~ms}$ caused (S-evoked increases in firing. Purkinje cell firing was monitored during $(S$-alone sessions of 40 trials before training $(\boldsymbol{G}, \boldsymbol{H})$, after $60 \mathrm{~min}$ of paired training $(\boldsymbol{I})$, and after an additional $60(\boldsymbol{J})$ and 90 min of training $(\boldsymbol{K}, \boldsymbol{L}) . \boldsymbol{M}$, Smoothed and averaged data from $\boldsymbol{H}-\boldsymbol{K}$ show an increase in $(S$-evoked firing after training (orange, cyan, and black curves) relative to the pretraining baseline (green curve).

electrical forelimb CS and strong electrical blink-inducing US without Purkinje cell recordings (Fig. 1A).

We conditioned five animals with a short ISI of $45 \mathrm{~ms}$ that does not support CR acquisition in rabbits and a long ISI of 145 $\mathrm{ms}$ that does (Fig. 1B). CF activity is delayed by $\sim 5 \mathrm{~ms}$ relative to MF activity for peripheral stimuli used in behavioral experiments, so these ISIs correspond to the 50 and $150 \mathrm{~ms}$ ISI training conditions used in subsequent Purkinje cell recording experiments for which training stimuli were delivered by direct MF and CF stimulation.
In an exemplar animal before training, the CS did not elicit a motor response, and a large CS-evoked motor response developed after training with an ISI of $145 \mathrm{~ms}$ (Fig. 1C). The CR was extinguished after subsequent training with a short ISI of 45 ms. All five animals exhibited significant CRs after training with an ISI of $145 \mathrm{~ms}$ (two-sample, two-tailed $t$ test with no assumption of equal population variances, $p<0.05)$, but not after training with a short ISI of $45 \mathrm{~ms}(p>0.05$; Fig. $1 D)$. These results are consistent with the requirement of an ISI $\sim 100 \mathrm{~ms}$ or longer for eyeblink conditioning in decerebrate ferrets.

\section{Purkinje cell recordings during long and short ISI training}

Purkinje cell activity was recorded from the cerebellar C3 eyeblink region (Hesslow, 1994a,b; Mostofi et al., 2010). In animals trained with long ISIs $(200-600$ $\mathrm{ms})$, Purkinje cells in this area exhibit CSevoked pauses in firing (Jirenhed et al., 2007; Jirenhed and Hesslow, 2011a). We recorded blink-related Purkinje cells in animals trained with a $150 \mathrm{~ms}$ ISI using direct stimulation of MFs and CFs as the CS and US, respectively. Before training, the naive response was characterized with CS-alone trials. Thereafter, paired CS-US training sessions were interleaved with CS-alone sessions to quantify learned changes in CS-evoked Purkinje cell firing.

For one representative Purkinje cell, $150 \mathrm{~ms}$ ISI training caused a pause in firing at a short latency after CS onset and peak modulation that preceded the timing of the expected US. Before training, the baseline CS-evoked response did not vary significantly relative to pretrial spontaneous activity (Fig. $2 A, B$ ). After $45 \mathrm{~min}$ of paired training, the cell exhibited a short pause in firing during the CS (Fig. 2C), which became more pronounced after an additional 20 min of paired training (Fig. $2 D-F)$. These results are consistent with behavioral data that indicate that a $150 \mathrm{~ms}$ ISI supports reliable CR acquisition.

In a different animal, we recorded a Purkinje cell during training with an ISI of $50 \mathrm{~ms}$, which is ineffective for behavioral CR acquisition. Before training, the Purkinje cell exhibited a modest increase in firing during the CS (Fig. 2G,H). After training with an ISI of $50 \mathrm{~ms}$, the Purkinje cell gradually responded with increased firing to the CS (Fig. $2 I-L$ ). After $180 \mathrm{~min}$ of training, the mean CS-evoked firing rate was approximately twice the pretrial background rate (Fig. $2 M$ ).

\section{ISI dependence of learned changes in Purkinje cell activity}

To determine the effect of training with different ISIs on the direction and amplitude of Purkinje cell modulation, we re- 

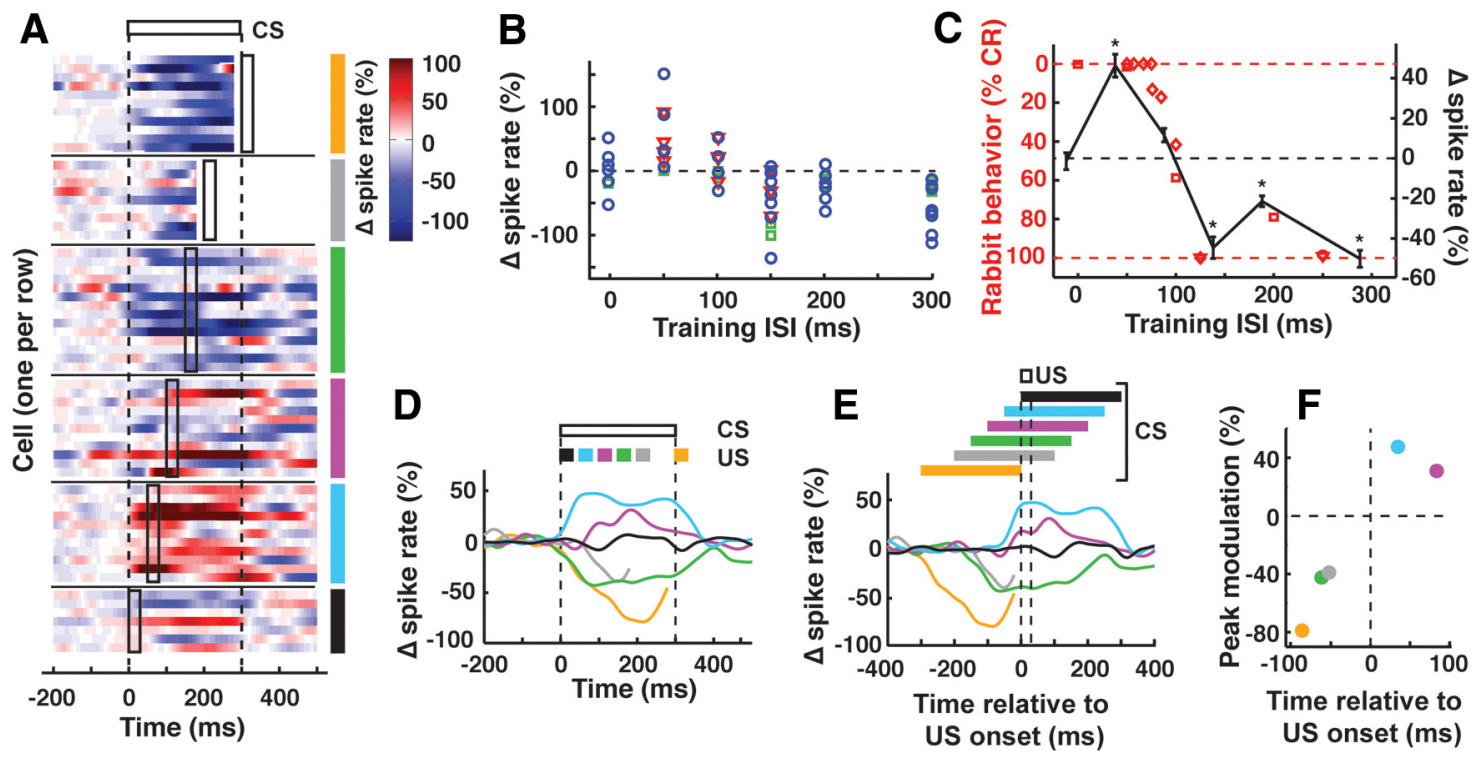

Figure 3. The direction and amplitude of Purkinje cell modulation corresponds to timing requirements of eyeblink conditioning. $A$, To isolate learning-related changes in Purkinje cell firing, pretraining spike rate curves were subtracted from posttraining data for all cells with at least two recorded CS-alone sessions. Each row shows data from a single cell, and increases and decreases in firing rate relative to the pretrial baseline are shown in red and blue, respectively. US timing during paired training is indicated with black rectangles, and each ISI is distinguished by colored

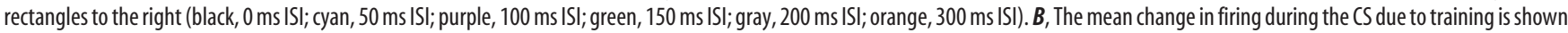
for all cells. The color and shape of data points specify whether recording began before training (blue circles), after some training with the same ISI (red triangles), or after training with a different ISI that was subsequently changed to the plotted ISI after recording a baseline CS-alone session (green squares). C, To compare the ISI dependence of neurophysiological and behavioral data, we replotted classic rabbit eyeblink conditioning data on a reversed $y$-axis (red symbols correspond to symbols in Fig. 1B), as well as the mean Purkinje modulation as a function of ISI from $\boldsymbol{B}$ (black line, \pm SEM). Asterisks indicate ISIs for which Purkinje modulation was significantly different from zero $(p<0.05)$. The curve showing Purkinje cell responses is shifted $5 \mathrm{~ms}$ backward to compensate for the shorter latency of climbing fiber activation that occurs with direct climbing fiber stimulation as the US. D, Mean change in firing rate due to training from all cells for each ISI. Curve color corresponds to the color of filled rectangles to the right of $\boldsymbol{A}$, and colored squares indicate the timing of US presentation on paired training sessions. $\boldsymbol{E}$, Mean data from $\boldsymbol{D}$ are plotted aligned to US onset with CS timing indicated by the rectangles at top. $\boldsymbol{F}$, The timing and amplitude of peak modulation relative to US onset are plotted by ISI, with circle color corresponding to curve colors in $\boldsymbol{D}$ and $\boldsymbol{E}$. Data for the $0 \mathrm{~ms} \mid \mathrm{SI}$ are not shown because no significant modulation relative to baseline was observed.

corded Purkinje cells in ferrets trained with ISIs of 0, 50, 100, 150, 200, and $300 \mathrm{~ms}$. For each cell, we quantified learning-related changes in Purkinje cell firing during the CS by computing the difference between mean firing rates during pretraining and posttraining CS-alone sessions (Fig. 3A; 55 cells, 63 training conditions). Cells recorded in ferrets trained with 50 or $100 \mathrm{~ms}$ ISIs exhibited increased CS-evoked firing, and longer ISIs produced CS-evoked pauses in firing (Fig. 3B). The direction and amplitude of modulation did not differ significantly between cells for which recording began before training, after some training at the same ISI, or after previous training at another ISI (Fig. 3B).

Population codes among neighboring Purkinje cells may be important for cerebellar processing due to downstream convergence. We estimated learning-related changes by averaging across all Purkinje cells for each ISI. The mean amplitude and direction of modulation during the CS for cells trained at a particular ISI corresponded to the temporal asymmetry of eyeblink conditioning (Fig. 3C).

Both conditioned eyeblink responses and learned pauses in Purkinje firing are well timed, so we investigated the time course of learned changes in Purkinje cell firing for each training ISI. The mean CS-evoked firing of cells recorded in animals trained with a long ISI of 150, 200, or $300 \mathrm{~ms}$ was reduced after training, and the peak responses were approximately timed to the ISI (Fig. 3D). Cells trained with a shorter ISI of 50 or $100 \mathrm{~ms}$ showed an increase in posttraining CS-evoked firing. The mean response of cells trained with an ISI of $0 \mathrm{~ms}$ did not show significant modulation after training.

To better visualize the contribution of US timing on learned changes in Purkinje cell firing, we realigned the mean population waveforms to the timing of US onset (Fig. 3E). If spike-timingdependent plasticity at PF synapses on Purkinje cells exclusively determines the time course of Purkinje cell modulation, the direction and amplitude of the modulation should be fixed for a given PF-CF delay. However, at a fixed delay relative to US onset, we observed that the amplitude and direction of the modulation differ markedly between populations of cells recorded under different training ISIs. For training ISIs $\geq 150 \mathrm{~ms}$ that support CR acquisition and lead to CS-evoked pauses in Purkinje cell firing, peak modulation occurred 50 to $100 \mathrm{~ms}$ before US onset (Fig. $3 \mathrm{~F}$, bottom left). In contrast, the peak increase of Purkinje cells recorded from animals trained with a 50 or $100 \mathrm{~ms}$ ISI occurred after US onset (Fig. $3 F$, top right). Data for $0 \mathrm{~ms}$ ISI are not plotted, because this population of cells did not vary significantly from pretrial baseline firing. These results support an alternative or supplementary biophysical mechanism to PF-Purkinje cell LTD for enforcing the observed temporal asymmetry of behavior.

\section{The direction of Purkinje cell modulation changes when the ISI is switched}

To confirm that observed effects were due to the training ISI, rather than an artifact of cell selection, we trained with both long and short ISIs sequentially in a subset of Purkinje cells.

Long, stable recordings permitted training of Purkinje cells with multiple ISIs in 12 cells. One exemplar cell exhibited a modest CS-evoked reduction in firing before training, and then developed a large CS-evoked increase in firing after training with a 50 ms ISI (Fig. 4A). Subsequent training with a $300 \mathrm{~ms}$ ISI caused a pause response that reverted to an increase in CS-evoked firing after switching back to $50 \mathrm{~ms}$ ISI training. The mean CS-evoked 

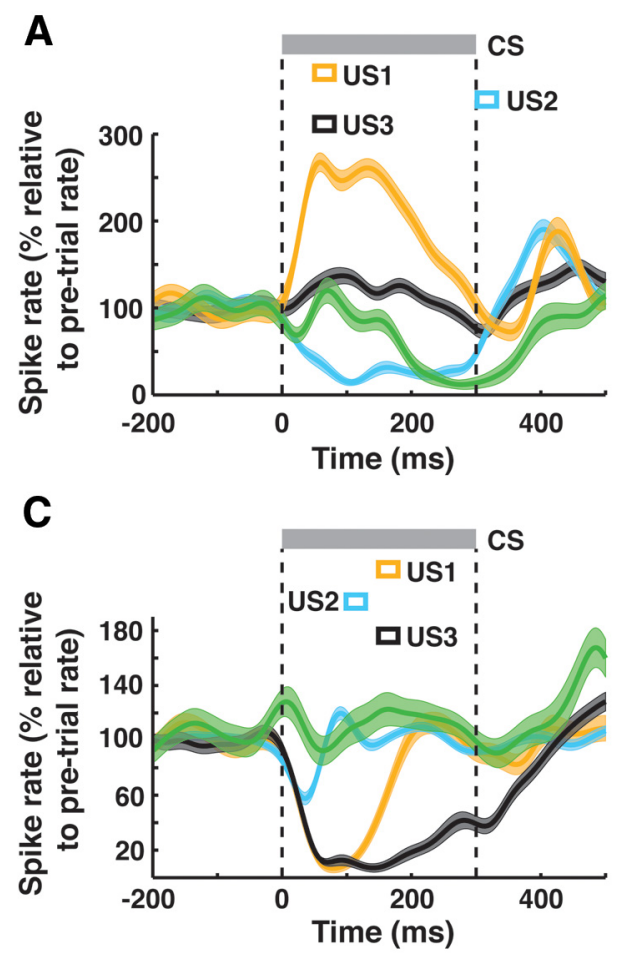

LTD at the PF-to-Purkinje cell synapse, a process that would be expected to occur at short ISIs.

Our main finding is that the acquisition of Purkinje cell CRs satisfies the same temporal requirements as the overt behavior. Consistent with previous behavioral studies and with our behavioral data from decerebrate ferrets (Fig. 1C,D), we observed CS-evoked pauses in Purkinje cell spiking after training with CS-US intervals $\geq 150$ ms (Jirenhed et al., 2007; Jirenhed and Hesslow, 2011a,b). Unexpectedly, we observed substantial increases in CS-evoked Purkinje cell spiking when training with short ISIs of $50 \mathrm{~ms}$.

The correspondence between our Purkinje cell data and previously published behavioral data from rabbits is illustrated in Figure 3C. For an ISI of 0 ms, Purkinje cells did not acquire CS-evoked learned responses, and no overt CRs occurred. At an ISI of $50 \mathrm{~ms}$, the CS elicits a strong increase in Purkinje cell firing that would be expected to prevent overt CRs. There is a small discrepancy around $100 \mathrm{~ms}$. Behavioral studies report $\sim 50 \%$ CRs at a 100 ms ISI, but there was no change in average Purkinje cell firing with this ISI. There are several possible explanations. One possibility is that the effective ISI for rabbit behavioral studies is greater due to a longer US $(50 \mathrm{~ms}, 60 \mathrm{~Hz})$ relative to our experiments $(28 \mathrm{~ms})$. Behavioral data show that a small change in ISI near $100 \mathrm{~ms}$ impacts the learning significantly. An effective ISI $\sim 20 \mathrm{~ms}$ longer in these rabbit experiments could account for the observed difference. Unfortunately, the temporal spike rate relative to pretrial firing was significantly higher than before training for both periods of $50 \mathrm{~ms}$ ISI training, and significantly less than before training for the $300 \mathrm{~ms}$ ISI condition $(p<$ 0.01; Fig. $4 B$ ).

Reversible bidirectional modulation was also observed when first training with a long ISI that supports the acquisition of a behavioral CR. In a cell recorded in a different ferret, a CS-evoked pause that developed after training with a $150 \mathrm{~ms}$ ISI was reduced in amplitude after subsequent training with an ISI of $100 \mathrm{~ms}$, and then reappeared after training again with an ISI of $150 \mathrm{~ms}$ (Fig. $4 C)$. Significant changes in CS-evoked Purkinje cell firing developed despite a relative shift of just $50 \mathrm{~ms}$ in CS and US timing (Fig. $4 D ; p<0.01$ ). Previous training with a different ISI did not influence the direction of Purkinje modulation in any recorded cell (data not shown), confirming that individual cells can acquire both increases and decreases in CS-evoked firing.

\section{Discussion \\ Relationship between behavioral and Purkinje cell conditioning}

The motivation behind this study was the apparent conflict between the fact that learning of overt conditioned responses does not occur with short ISIs (Schneiderman and Gormezano, 1964; Smith, 1968; Smith et al., 1969; Salafia et al., 1980) and the hypothesis that the synaptic learning mechanism in conditioning is

resolution of both the Purkinje cell and the behavioral data is insufficient to evaluate this possibility. Patterson (1970) reported CR acquisition with an ISI of $50 \mathrm{~ms}$, but the US used in this study was an air puff, which has a slower onset than the electrical stimuli used by others. The latencies of unconditioned blinks to air puff are considerably longer than to electrical stimuli (MarshallGoodell et al., 1992), suggesting that the effective ISI in the study by Patterson (1970) may have been longer than $50 \mathrm{~ms}$.

We showed previously that the Purkinje cell CR matches several features of the behavioral CR. Purkinje cell CRs are acquired during paired CS-US presentations and extinguished during CSalone presentations. It reappears with considerable savings when paired stimulation is resumed after extinction (Jirenhed et al., 2007). The timing of the Purkinje cell CR depends on the ISI in the same way as the overt CR and is changed in the same way by changes in CS parameters (Svensson et al., 2010; Jirenhed and Hesslow, 2011a,b). The addition to this list of the minimum ISI requirement further strengthens the hypothesis that the Purkinje cell CR is the main driver of the overt CR.

\section{The nature of the excitatory Purkinje cell response}

The learned excitatory Purkinje cell response we observed at short ISIs has not been reported previously. There are many unanswered questions about the properties of this form of modula- 
tion and the conditions under which it occurs. We did not test for associativity with traditional criteria such as unpaired CS-US presentations (Kehoe and Macrae, 2002). However, in previous studies where the CS was repeatedly presented alone for long periods of time, we never observed excitatory responses (Jirenhed et al., 2007). Development of these responses seems to require paired CS-US presentations at a specific range of ISIs. The excitatory responses did not develop at an ISI of $0 \mathrm{~ms}$. Thus, it is unlikely that they are caused by the kind of long-term potentiation described previously after PF stimulation without concomitant CF activation (Jörntell and Ekerot, 2002).

\section{What is the mechanism of the minimum ISI requirement?}

The standard view of the synaptic mechanism underlying conditioning is that it is mediated by PF-Purkinje cell LTD (Koekkoek et al., 2003; Yamazaki and Tanaka, 2009). However, LTD as traditionally conceived cannot easily account for the results, because LTD would be effective at short delays between PF and CF input. A large number of studies have confirmed that PF-Purkinje cell LTD is most pronounced for PF-CF delays close to zero (Ekerot and Kano, 1989; Karachot et al., 1994).

A resolution of this paradox might be provided by three studies that have reported PF-Purkinje cell LTD to be most effective when PFs are activated $\sim 100 \mathrm{~ms}$ before CFs (Chen and Thompson, 1995; Wang et al., 2000; Safo and Regehr, 2008). These findings fit with behavioral studies using gain adaptation of the vestibulo-ocular reflex (Raymond and Lisberger, 1998) and would seem to strengthen the case for LTD as a mechanism for conditioning. However, there are difficulties with this interpretation.

Although they report that LTD is strongest when the PF-CF delay is $\sim 100 \mathrm{~ms}$, all three studies found some LTD when the delay was zero. It could be argued that weak LTD at short ISIs would be consistent with weak conditioning at such ISIs. However, our data did not just show weaker Purkinje cell suppression at short ISIs, but rather a strong increase in firing. Chen and Thompson (1995) found strong LTD when the PF-CF interval was $250 \mathrm{~ms}$ in 100 trials, but no LTD when the inputs were simultaneous. However, with 600 trials, which is actually closer to what is required for overt conditioning, LTD also occurred with both zero and negative PF-CF delays. Safo and Regehr (2008) used a protocol that was closer to those used for conditioning in intact animals. The CS was a burst of seven PF pulses $(100 \mathrm{~Hz})$ followed by a single CF pulse repeated 30 times every $10 \mathrm{~s}$. The authors found that a PF-CF delay of $\sim 80 \mathrm{~ms}$ was optimal for obtaining LTD. However, they also found substantial LTD with a zero and even negative ISIs and almost no LTD at $330 \mathrm{~ms}$, which is close to optimal for eyeblink conditioning. Another problematic aspect of this study is the rate of learning. For instance, with the $80 \mathrm{~ms}$ PF-CF delay, the full LTD effect was present after only 5 min of training with 30 trials. In contrast, hours of training with hundreds of trials are necessary to obtain blink CRs or Purkinje cell CRs in vivo.

The paper by Wang et al. (2000) has problems similar to those of the other studies. There was clear LTD with an ISI of $<0 \mathrm{~ms}$ with intertrial intervals of only $2 \mathrm{~s}$. The learning was also orders of magnitude faster than that seen during conditioning.

A large number of discrepancies between LTD and conditioning have been reported to date (Hesslow et al., 2013). For instance, LTD is much faster than conditioning, it cannot account for the timing of CRs, and PF-Purkinje cell synapses are not depressed after conditioning (Jirenhed and Hesslow, 2011b). We also recently showed that, although LTD is normally induced by single CF stimuli, USs consisting of single CF impulses do not support conditioning, which requires bursts of olivary impulses (Rasmussen et al., 2013). We can now add the minimum ISI requirement for acquisition of Purkinje cell CRs.

Direct comparison between the timing-dependent plasticity studied in vitro and the effects observed in the present in vivo work is problematic, and not only because of the difference between the preparations. In the standard conditioning protocol we used, the mossy fiber CS, and consequently the PF inputs to neurons in the cerebellar cortex, continues throughout and often far beyond the ISI (Jirenhed and Hesslow, 2011a,b). Therefore, the first PF input precedes the CF input by the full ISI, but during the remainder of the CS, PF inputs precede the CF inputs at gradually decreasing intervals until they become concurrent. When the CS outlasts the ISI, as in experiments reported here, CF input will precede the later parts of the PF input. Thus, many PF-CF delays, both positive and negative, will actually be represented in the same trials in a standard conditioning protocol. Yet the direction and amplitude of learned changes in Purkinje cell spiking is determined by the ISI, suggesting that the cerebellar circuits recognize the onset of these stimulus trains for the purpose of inducing plasticity and acquiring Purkinje CRs. Plasticity studies in vitro are generally not designed to measure this temporal profile of activity, thus limiting the conclusions that can be drawn from the in vitro work discussed here.

In short, our findings suggest that LTD of the parallel fiberPurkinje cell synapses is unlikely to be the primary mechanism underlying conditioning, a conclusion that is also supported by recent evidence from genetically modified mice (Schonewille et al., 2011).

An alternative to LTD that we are currently addressing in our laboratory is long-term potentiation of the inhibitory action of molecular layer interneurons, a mechanism that has been demonstrated previously in vivo (Jörntell and Ekerot, 2002; Jirenhed et al., 2013). The temporal properties of this form of plasticity are not well studied, but we suspect that that it would raise the same problems of timing and minimum ISI as Purkinje cell LTD. A full understanding of conditioning at the neural circuit level may require consideration of other forms of plasticity, perhaps in combination (Gao et al., 2012), as well as the effects of more subtle aspects of the stimulus patterns than have hitherto been recognized.

\section{References}

Albus J (1971) A theory of cerebellar function. Math Biosci 10:25-61. CrossRef

Chen C, Thompson RF (1995) Temporal specificity of long-term depression in parallel fiber-Purkinje synapses in rat cerebellar slice. Learn Mem 2:185-198. CrossRef Medline

Citri A, Malenka RC (2008) Synaptic plasticity: multiple forms, functions, and mechanisms. Neuropsychopharmacology 33:18-41. CrossRef Medline

Dan Y, Poo MM (2006) Spike timing-dependent plasticity: from synapse to perception. Physiol Rev 86:1033-1048. CrossRef Medline

Ekerot CF, Kano M (1989) Stimulation parameters influencing climbing fibre induced long-term depression of parallel fibre synapses. Neurosci Res 6:264-268. CrossRef Medline

Gallistel C (1990) The organization of learning. Cambridge, MA: Bradford Books/MIT.

Gao Z, van Beugen BJ, De Zeeuw CI (2012) Distributed synergistic plasticity and cerebellar learning. Nat Rev Neurosci 13:619-635. CrossRef Medline

Hebb DO (1949) The organization of behavior: a neuropsychological theory. New York: Wiley.

Hesslow G (1994a) Correspondence between climbing fibre input and motor output in eyeblink-related areas in cat cerebellar cortex. J Physiol 476:229-244. Medline 
Hesslow G (1994b) Inhibition of classically conditioned eyeblink responses by stimulation of the cerebellar cortex in the decerebrate cat. J Physiol 476:245-256. Medline

Hesslow G, Ivarsson M (1994) Suppression of cerebellar Purkinje cells during conditioned responses in ferrets. Neuroreport 5:649-652. CrossRef Medline

Hesslow G, Yeo CH (2002) The functional anatomy of skeletal conditioning. In: A neuroscientist's guide to classical conditioning (Moore JW, ed), pp 86-146. New York: Springer.

Hesslow G, Jirenhed DA, Rasmussen A, Johansson F (2013) Classical conditioning of motor responses: what is the learning mechanism? Neural Netw 47:81-87. CrossRef Medline

Ito M (2001) Cerebellar long-term depression: characterization, signal transduction, and functional roles. Physiol Rev 81:1143-1195. Medline

Ito M, Sakurai M, Tongroach P (1982) Climbing fibre induced depression of both mossy fibre responsiveness and glutamate sensitivity of cerebellar Purkinje cells. J Physiol 324:113-134. Medline

Jirenhed DA, Hesslow G (2011a) Learning stimulus intervals-adaptive timing of conditioned Purkinje cell responses. Cerebellum 10:523-535. CrossRef Medline

Jirenhed DA, Hesslow G (2011b) Time course of classically conditioned Purkinje cell response is determined by initial part of conditioned stimulus. J Neurosci 31:9070-9074. CrossRef Medline

Jirenhed DA, Bengtsson F, Hesslow G (2007) Acquisition, extinction, and reacquisition of a cerebellar cortical memory trace. J Neurosci 27:24932502. CrossRef Medline

Jirenhed DA, Bengtsson F, Jörntell H (2013) Parallel fiber and climbing fiber responses in rat cerebellar cortical neurons in vivo. Front Syst Neurosci 7:16. Medline

Jörntell H, Ekerot CF (2002) Reciprocal bidirectional plasticity of parallel fiber receptive fields in cerebellar Purkinje cells and their afferent interneurons. Neuron 34:797-806. CrossRef Medline

Karachot L, Kado RT, Ito M (1994) Stimulus parameters for induction of long-term depression in in vitro rat Purkinje cells. Neurosci Res 21:161168. Medline

Kehoe E, Macrae M (2002) Fundamental behavioral methods and findings in classical conditioning. In: A neuroscientist's guide to classical conditioning (Moore JW, ed.), pp 171-231. New York: Springer-Verlag.

Kellett DO, Fukunaga I, Chen-Kubota E, Dean P, Yeo CH (2010) Memory consolidation in the cerebellar cortex. PLoS One 5:e11737. CrossRef Medline

Koekkoek SK, Hulscher HC, Dortland BR, Hensbroek RA, Elgersma Y, Ruigrok TJ, De Zeeuw CI (2003) Cerebellar LTD and learningdependent timing of conditioned eyelid responses. Science 301:17361739. CrossRef Medline
Marr D (1969) A theory of cerebellar cortex. J Physiol 202:437-470. Medline

Marshall-Goodell B, Kehoe EJ, Gormezano I (1992) Laws of the unconditioned reflex in the rabbit nictitating membrane preparation. Psychobiology 20:229-237.

Mostofi A, Holtzman T, Grout AS, Yeo CH, Edgley SA (2010) Electrophysiological localization of eyeblink-related microzones in rabbit cerebellar cortex. J Neurosci 30:8920-8934. CrossRef Medline

Patterson MM (1970) Classical conditioning of the rabbit's (Oryctolagus cuniculus) nictitating membrane response with fluctuating ISI and intracranial CS. J Comp Physiol Psychol 72:193-202. CrossRef Medline

Rasmussen A, Jirenhed DA, Zucca R, Johansson F, Svensson P, Hesslow G (2013) Number of spikes in climbing fibers determines the direction of cerebellar learning. J Neurosci 33:13436-13440. CrossRef Medline

Raymond JL, Lisberger SG (1998) Neural learning rules for the vestibuloocular reflex. J Neurosci 18:9112-9129. Medline

Safo P, Regehr WG (2008) Timing dependence of the induction of cerebellar LTD. Neuropharmacology 54:213-218. CrossRef Medline

Salafia WR, Lambert RW, Host KC, Chiala NL, Ramirez JJ (1980) Rabbit nictitating membrane conditioning: lower limit of the effective interstimulus interval. Anim Learn Behav 8:85-91. CrossRef

Schneiderman N, Gormezano I (1964) Conditioning of the nictitating membrane of the rabbit as a function of the CS-US interval. J Comp Physiol Psych 57:188-195. CrossRef

Schonewille M, Gao Z, Boele HJ, Veloz MF, Amerika WE, Simek AA, De Jeu MT, Steinberg JP, Takamiya K, Hoebeek FE, Linden DJ, Huganir RL, De Zeeuw CI (2011) Reevaluating the role of LTD in cerebellar motor learning. Neuron 70:43-50. CrossRef Medline

Smith MC (1968) CS-US interval and US intensity in classical conditioning of the rabbit's nictitating membrane response. J Comp Physiol Psychol 66:679-687. CrossRef Medline

Smith MC, Coleman SR, Gormezano I (1969) Classical conditioning of the rabbit's nictitating membrane response at backward, simultaneous, and forward CS-US intervals. J Comp Physiol Psychol 69:226-231. CrossRef Medline

Svensson P, Jirenhed DA, Bengtsson F, Hesslow G (2010) Effect of conditioned stimulus parameters on timing of conditioned Purkinje cell responses. J Neurophysiol 103:1329-1336. CrossRef Medline

Wang SS, Denk W, Häusser M (2000) Coincidence detection in single dendritic spines mediated by calcium release. Nat Neurosci 3:1266-1273. CrossRef Medline

Wetmore DZ, Mukamel EA, Schnitzer MJ (2008) Lock-and-key mechanisms of cerebellar memory recall based on rebound currents. J Neurophysiol 100:2328-2347. CrossRef Medline

Yamazaki T, Tanaka S (2009) Computational models of timing mechanisms in the cerebellar granular layer. Cerebellum 8:423-432. CrossRef Medline 